\title{
Kayseri İl Sağlık Müdürlüğü Sağlıklı Hayat Merkezleri Diyet Poliklinikleri 2018 Yılı Verilerinin Değerlendirilmesi
}

\author{
Mehmet Emin ÖZDEMİR ๑ $₫$, Serkan YILDIZ ๑, Ali Ramazan BENLİ ๑, Nadir Emre ÜNSAL ๑, \\ Berkan ASLAN (1) \\ Kayseri İl Sağlık Müdürlüğü, Kayseri, Türkiye \\ Bu makaleye yapılacak atıf: Özdemir ME, Yıldız S, Benli AR, Ünsal NE, Aslan B. Kayseri İl Sağlık Müdürlüğü Sağlıklı Hayat Merkezleri Diyet Poliklinikleri 2018 Yılı Verilerinin \\ Değerlendirilmesi. Türk Diyab Obez 2020;3: 249-252.
}

\begin{abstract}
ÖZ
Amaç: Bu çalışma Kayseri ilinde 2018 yılında 5 adet sağlıklı yaşam merkezindeki diyet polikliniklerine başvuranların vücut ağırlıklarının değişimini değerlendirmek amacı ile yapılmıştır.

Gereç ve Yöntemler: Bu çalışma 2018 yılında Kayseri’de birinci basamak sağlık hizmetleri alanında diyetisyen polikliniklerine başvuran 5.462 kişinin verileri incelenerek yapılmıştır. Halk Sağlı̆̆ 1 Yönetim Sistemi (HSYS) üzerinden veriler taranmış ve SPSS 21.0 ’a aktarılmıştır. Beden Kütle İndeks'leri (BKİ) hesaplanarak obezite sınıflandırmaları yapılmıştır. Çalışma için Kayseri İl Sağlık Müdürlügü’nden yazılı izin ve Erciyes Üniversitesi Klinik Olmayan Araştırmalar Etik Kurulu’ndan etik onay alınmıştır.

Bulgular: Kayseri ilinde bulunan 5 adet sağlıklı yaşam merkezindeki diyetisyen polikliniklerine 2018 yılında 18 yaş üstü 5,462 kişi başvurmuştur. Başvuranların \%58.4'ünün BKİ'sinin 30'un üstünde olduğu görülmüştür. En az 1 defa gelenlerin \%53,2'si evre 1 obezdir. En az 2 defa gelenlerin \%52,7’si evre 1 obezdir. İkinci kez gelen obez bireylerin ilk geliş BKİ ortancaları 34,7 iken ikinci gelişlerindeki BKİ ortancaları 33,1 olarak bulunmuştur. Ortancalar kıyaslandığında aradaki farklar istatistiksel olarak anlamlıdır.(p<0,05).

Sonuç: Çalışmamızda sağlıklı hayat merkezlerinde hizmet vermekte olan diyet polikliniklerinin kilo vermede etkin olduğu tespit edilmiştir. Sağlıklı hayat merkezleri içerisinde spor salonları; fizyologlar, spor hocalarının da görevlendirilerek oluşturulması obeziteyle mücadeleye katkı sunacaktır.
\end{abstract}

Anahtar Sözcükler: Obezite, Diyet, BKİ, Sağlıklı hayat merkezi

\section{Evaluation of 2018 Data of Kayseri Provincial Health Directorate Healthy Life Centers Diet Polyclinics}

\begin{abstract}
Aim: This study was carried out to evaluate the change of body weights of the applicants to the diet polyclinics in 5 wellness centers in Kayseri in 2018.

Material and Methods: This study was conducted by examining the data of 5.462 people who applied to dietitian outpatient clinics in the field of primary health care in Kayseri in 2018. Data were scanned through the Public Health Management System (HSYS) and transferred to SPSS 21.0. Obesity classifications were made by calculating Body Mass Index (BMI). Written permission from Kayseri Provincial Health Directorate and ethical approval from Erciyes University Non-Clinical Researches Ethics Committee were obtained for the study.

Results: In 2018, 5462 people over the age of 18 applied to dietician outpatient clinics in 5 healthy life centers in Kayseri. It was observed that $58.4 \%$ of the applicants had over 30 BMI. $53.2 \%$ of those who come at least once are stage 1 obese. $52.7 \%$ of those who come at least twice are stage 1 obese. While the median BMI of obese individuals who came for the second time was 34.7 at the first visit, their BMI median at the second visit was found to be 33.1. When the medians are compared with the Wilcoxon test, the differences are statistically significant.

Conclusion: In our study, it was determined that diet polyclinics that serve in health centers are effective in losing weight. Gyms within healthy life centers; The creation of physiologists and sports coaches will contribute to the fight against obesity.
\end{abstract}

Key Words: Obesity, Diet, BMI, Wellness center

ORCID: Mehmet Emin Özdemir / 0000-0001-6043-5063, Serkan Y1ldız / 0000-0001-6610-2120, Ali Ramazan Benli / 0000-0003-0039-1497, Nadir Emre Ünsal / 0000-0002-3847-0265, Berkan Aslan / 0000-0002-2549-9771

Yazışma Adresi / Correspondence Address:

DOI: $10.25048 /$ tudod.713326

Mehmet Emin ÖZDEMİR

Kayseri İl Sağllk Müdürlüğü, Kayseri, Türkiye

Tel: 0 (533) 6169229 • E-posta: drmehmetemin@yahoo.com

Geliş tarihi / Received : :02.04.2020 Revizyon tarihi / Revision : 10.10 .2020 Kabul tarihi / Accepted : $: 30.10 .2020$ 


\section{GİRİ̧ ve AMAÇ}

Obezite, vücutta yağ kütlesinin artışı ile karakterize, organları ve sistemleri etkileyerek ölüme neden olan bir hastalıktır (1). Obezite oluşmasında harcanan enerjiye oranla daha fazla enerji alınması önemli bir sebeptir. Bu enerji dengesizliğinin yanında, medeni durum, mesleki koşullar, eğitim durumu, sosyoekonomik düzey, genetik faktörler ile günlük fiziksel aktivitedeki azalma obezite oluşmasında etkili olmaktadır $(2,3)$.

Dünya Sağlık Örgütü (DSÖ) tarafından obezite, "yağ dokusunun, sağlıkla ilgili olumsuz sonuçlara yol açacak ölçüdeartması" olarak tanımlanmaktadır. Gelişmiş ve gelişmekte olan ülkelerde ve ülkemizde, epidemik boyutlara ulaşan önlenebilir bir sorun olmakla kalmayıp, küresel ölçekte önemli bir sağlık sorunu olarak ortaya çıkmaktadır (4-8). Obezitenin \%30-70'inden genetik faktörler sorumlu olsa da, yanlış beslenme alışkanlıkları, yanlış yaşam davranışları, azalmış fiziksel aktiviteye yol açarak enerji dengesizliklerine ve gelișmiș toplumlar bașta olmak üzere obezitenin artmasına neden olmaktadır $(5,8)$. Obezitenin önlenmesi ve tedavisi halk sağlığının korunması açısından önemli bir yaklaşımdır. Bu amaçla birinci basamak sağlık hizmetlerinde sağlıklı yaşam merkezleri kurulmuş ve bu merkezlerde sağlıklı beslenme ve fiziksel aktivite danışmanlığı, kanser taramaları gibi faaliyetler yürütülmektedir (9).

Yetişkin bir insanın obez veya fazla kilolu olarak tanımlanmasında, beden kütle indeksi(BKİ) kullanılır. Şişmanlığın saptanmasında en geçerli yöntem vücutta yağ miktarının saptanmasıdır ve vücut analizi yöntemi ile bu yapılabilmektedir. Vücut yağ miktarının yetişkinler için; erkeklerde \%25, kadınlarda \%35'in üzerinde, çocuk ve adölesanlarda ise erkeklerde $\% 25$, kızlarda $\% 30$ 'un üzerinde olması şişmanlık olarak değerlendirilir (10). Vücut analizinin her hasta için yapılması, gerekli cihaz, deneyimli personel ve hasta yoğunluğu nedeniyle pratikte çok mümkün olamamaktadır. Bu nedenle BKİ kullanılmaktadır $(11,12)$.

Bu çalışma Kayseri ilinde 2018 yılında 5 adet sağlıklı yaşam merkezinde bulunan diyet polikliniklerine başvuran bireylerin vücut ağırlıklarının değişimini değerlendirmek amacı ile yapılmıştır.

\section{GEREÇ ve YÖNTEMLER}

Bu çalışmada 2018 yllı boyunca Kayseri ili geneli birinci basamak sağlık hizmetleri alanında diyetisyen polikliniklerine başvuran 5.462 kişinin verileri incelenerek yapılmıştır. Halk Sağlığı Yönetim Sistemi (HSYS) üzerinden veriler taranmış ve SPSS 21.0’a aktarılmıştır. Çalışma için Kayseri İl Sağlık Müdürlügü’nden yazılı izin ve Erciyes Üniversitesi Klinik Olmayan Araştırmalar Etik Kurulu’ndan 11.03.2020 tarih ve karar numarası 2020/192 ile etik onay alınmıştır.

Çalışmaya 18 yaş üstü kişiler dâhil edilmiştir. BKİ; vücut ağırlığının kilogram cinsinden boy uzunluğunun metre cinsinden karesine bölünmesi ile hesaplanmıştır. BKİ' si 18,50 altı bireyler zayıf, 18,50 ve 24.99 arası olanlar normal, 25,00 ve 29.99 arası olanlar hafif şişman, 30,00 ve üstü obez olarak gruplandırılmıștır. 30,00-34,99 arası evre 1 obez, $35,00-39,99$ arası evre 2 obez, 40,00 ve üstü evre $3 \mathrm{obez}$ olarak sınıflandırılmıştır (3).

İstatistiksel analizler için SPSS paket programı kullanılmıştır. İstatistiksel anlamlılık $\mathrm{p}<0,05$ değerleri için kabul edilmiştir. BKİ' ler karşılaştırılmak istendiğinde ortanca değerler, başvuran kişilerin BKİ durumuna göre sayıları frekans ve yüzdelerle, polikliniğe başvuran kişi sayıları da frekans ve yüzdeler kullanılarak verilmiştir. Verilerin normal dağılıma uygunluğu Kolmogorov-Smirnov normallik testi ile değerlendirilmiş olup, normal dağılım göstermeyen veriler için Wilcoxon testi kullanılmıştır.

\section{BULGULAR}

Kayseri ilinde bulunan 5 adet sağlıklı yaşam merkezindeki diyetisyen polikliniklerine 2018 yılında 18 yaş üstü 5.462 kişi başvurmuştur. Başvuru yapan kişilerin BKİ aralıklarına göre dağılımı Tablo 1 de verilmiştir.

En az 1 defa gelenlerin \%53,2'si evre 1 obez olduğu görülmüş olup en az 2 defa gelenlerin \%52,7'si evre 1 obezdir (Tablo 2).

Diyetisyen polikliniğine 3 ay içinde ikinci kez gelen 18 yaş üstü 987 kişinin ise ilk gelişine göre BKİ değişimleri obezite durumuna göre kıyaslanmıştır. İkinci gelişteki BKİ ortancaları ile ilk gelişlerindeki BKİ ortancaları kıyaslanmıştır.

Diyetisyen polikliniğine ikinci kez gelen zayıf bireylerin ilk geliş BKİ ortancaları 16,39 iken ikinci gelişlerindeki BKİ ortancaları 17,01 olarak bulunmuştur. Diyetisyen polikliniğine ikinci kez gelen normal ağırlıktaki bireylerin ilk geliş BKİ ortancaları 24,2 iken ikinci gelişlerindeki BKİ ortancaları 22,9 olarak bulunmuştur. Diyetisyen polikliniğine ikinci kez gelen hafif şişman bireylerin ilk geliş BKİ ortancaları 28,2 iken ikinci gelişlerindeki BKİ ortancaları 26,7 olarak bulunmuştur. Diyetisyen polikliniğine ikinci kez gelen obez bireylerin ilk geliş BKİ ortancaları 34,7 iken ikinci gelişlerindeki BKİ ortancaları 33,1 olarak bulunmuştur. (Tablo 3).

\section{TARTIŞMA}

$\mathrm{Bu}$ çalışmada diyetisyene başvuranların \%58,4'ünün BKİ'i 30 'un üzerinde bulunmuştur. Ankara'da Çayır ve ark.nın 2011 yılında yaptığı çalışmada Beslenme ve Diyet Bölümü’ne başvuranlarda obezite \%28 olarak bulunmuştur (14). Bu fark Ankara'da yapılan çalışmanın 2 aylık bir süreci kapsamasından, polikliniklerden sevk edilen kronik rahatsızlı̆̆ 1 olan hastaların çokluğundan kaynaklanıyor olabilir. Bizim çalışmamızın da birinci basamak diyet polikliniğinde yapılmış olmasından kaynaklanıyor olabilir. Özel bir hastanenin beslenme ve diyet polikliniğine başvuran rastgele seçilmiş 100 birey üzerinde yapılan bir tez çalışmasında; araştırmaya katılan bireylerin yalnızca \%11,0’ının BKİ'i normal sinır- 
Tablo 1: Diyetisyen Polikliniklerine Başvuran Kişilerin BKİ Aralıklarına Göre Dağılımı

\begin{tabular}{lccc}
\hline BKİ Durumu & Erkek (\%) & Kadın (\%) & Toplam (\%) \\
\hline Zayıf & $27(0,5)$ & $109(2,0)$ & $136(2,5)$ \\
\hline Normal & $50(0,9)$ & $477(8,7)$ & $527(9,6)$ \\
\hline Hafif şişman & $241(4,4)$ & $1.366(25,0)$ & $1.607(29,4)$ \\
\hline Obez & $346(6,3)$ & $2.846(52,1)$ & $3.192(58,4)$ \\
\hline Toplam & $664(12,2)$ & $4.798(87,8)$ & $5.462(100,0)$ \\
\hline
\end{tabular}

Tablo 2: Obez Kişilerin Geliş Durumuna Göre Obezite Evrelemesi

\begin{tabular}{lcc}
\hline & İlk Geliş & İkinci Geliş \\
\hline BKI & $\mathbf{n}(\%)$ & $\mathbf{n}(\%)$ \\
\hline Evre 1 obez & $1.701(53,2)$ & $364(52,7)$ \\
\hline Evre 2 obez & $999(31,3)$ & $234(33,9)$ \\
\hline Evre 3 obez & $492(15,4)$ & $93(13,4)$ \\
\hline Toplam & $3.192(100,0)$ & $691(100,0)$ \\
\hline
\end{tabular}

Tablo 3: İkinci Kez Polikliniğine Gelen Kişilerin BKİ Ortancalarının Karşılaştırılması

\begin{tabular}{|c|c|c|c|}
\hline & & $\begin{array}{c}\text { Ortanca } \\
(\text { min-max })\end{array}$ & $\underset{\text { değeri }}{p}$ \\
\hline \multirow{2}{*}{$\begin{array}{l}\text { Zayıf } \\
(n=18)\end{array}$} & İlk BKİ & $16,4(14,2-18,1)$ & 0,001 \\
\hline & 2.BKİ & $17,0(14,8-18,7)$ & \\
\hline \multirow{2}{*}{$\begin{array}{l}\text { Normal } \\
(n=41)\end{array}$} & İlk BKİ & $24,2(18,8-25,0)$ & 0,002 \\
\hline & 2.BKİ & $22,9(19,6-25,7)$ & \\
\hline \multirow{2}{*}{$\begin{array}{l}\text { Hafif şişman } \\
(n=237)\end{array}$} & İlk BKİ & $28,2(25,0-30,0)$ & $<0,0001$ \\
\hline & 2.BKİ & $26,7(20,6-30,2)$ & \\
\hline \multirow{2}{*}{$\begin{array}{l}\text { Obez } \\
(n=691)\end{array}$} & İlk BKİ & $34,7(30,0-64,3)$ & $<0,0001$ \\
\hline & 2.BKİ & $33,10(24,3-52,8)$ & \\
\hline
\end{tabular}

larda bulunmuş; \%27,0’ının BKİ'i ise $>35 \mathrm{~kg} / \mathrm{m}^{2}$ 'den yüksek bulunmuştur (15). Bu fark yine çalışmanın 2 aylık bir süreçte ve az kişi üzerinde yapılmasından kaynaklanmış olabilir (15). Küresel Hastalık Yükü (Global Burden of Disease: GBD) Obezite İşbirliği Grubu’nun 2015 yılı raporuna göre, dünyada obez nüfus 711,4 milyona (107,7 milyon çocuk ve 603,7 milyon yetişkin) ulaşmıştır. DSÖ tahminlerine göre, 2016 yllında dünya genelinde, yetişkinlerin \%39’u fazla kilolu ve \%13'ü obezdir. Bu çalışmada obez başvuru yüzdeleri daha fazladır. DSÖne göre toplumun \%25’i obezdir (16). İran’n kuzeyinde 20-70 yaş aralığında yapılan bir çalışmada obezite prevalansı \%34.8 (5); Türk Erişkinlerinde Kalp Hastalığ 1 ve Risk Faktörleri (TEKHARF) çalışmasında \%28.6; Türkiye Erişkin Kalp Sağlığı ve Hipertansiyon Araştırması ve Risk
Faktörleri (TOHTA) çalışmasında \%25.2; Türkiye Diyabet Epidemiyoloji II (TURDEP II) çalışmasında \%31.2; Türkiye Metabolik Sendrom Araştırması'nda çalışmasında \%36.2 olarak bulunmuştur (17-20). Bu çalışmada obezite ile başvuranların yüzdesi yüksek bulunmuştur. Bu durum beslenme ve diyet polikliniğinde yapılan çalışmaya kilo sorunu olan kişilerin daha çok başvurmasından kaynaklanıyor olabilir. Süleyman Demirel Üniversitesi Tip Fakültesinde diyet polikliniğinde Mayıs 2010- Aralık 2014 tarihleri arasında vücut analizi ölçümü yapılan 2.527 erkek ve 7.267 kadın üzerinde yapilan çalışmada obezite prevalansı \%50,5 bulunmuştur (21). Bizim çalışmamızda da benzer bir oran bulunmuştur. Her iki çalışmanın da uzun süreler ve fazla katılımcıyla yapılmasından kaynaklanıyor olabilir.

$\mathrm{Bu}$ çalışmada diyet polikliniğine gelenlerin \%6.3'ü obez erkek, \%52,1'i obez kadındı. Ankara Üniversitesi Tip Fakültesinde 2011 yılında yapılan çalışmada çalışmaya katılanların \%35,1'i obez kadın, \%16,4'ü obez erkekti (14).

Türkiye Diyabet Epidemiyoloji çalışmasında; obezite prevalansı, bütün coğrafi bölgeler ve yerleşim birimlerinde kadınlarda, erkeklerden daha yüksek olmaktadır. Bu çalışmada da kadınlarda obezite yüzdesi yüksek bulunmuştur ama bunun obezitenin kadınlarda fazla olmasından mı ya da çalışmaya katılanlar da kadınların fazla olmasından mı kaynaklandığı kesin değildir (22).

Bu çalışmada obez bireyler BKİ kategorilerine göre incelendiğinde; ilk kez başvuranların \%53,2'sinin evre $1 \mathrm{obez} \%$ 31,3'ünün evre 2 obez, \%15.4'ünün ise evre 3 obez olduğu görülmektedir. Saygın ve ark. tarafından yapılan çalışmada obez bireylerin \%49,4'ü evre 1 obez, \% 29,5’1 evre 2 obez, \%20,9'u evre 3 obez bulunmuştur. İki çalışmada da evre 1 obezler fazladır (21).

$\mathrm{Bu}$ çalışmada diyetisyen polikliniğine ikinci kez gelen normal ağırlıktaki bireylerin ilk geliş BKİ ortancaları 24,2 iken ikinci gelişlerindeki BKİ ortancaları 22,9 olarak bulunmuştur. Diyetisyen polikliniğine ikinci kez gelen hafif şişman bireylerin ilk geliş BKİ ortancaları 28,2 iken ikinci gelişlerindeki BKİ ortancaları 26,7 olarak bulunmuştur. Diyetisyen polikliniğine ikinci kez gelen obez bireylerin ilk geliş BKİ ortancaları 34,7 iken ikinci gelişlerindeki BKİ ortancaları 
33,1 olarak bulunmuştur. Ankara Üniversitesi Tip Fakültesinde 2011 yılında yapılan bir çalışmada Beslenme ve Diyet Bölümü'ne başvuranlarda obezite oranı, daha önce obezite tedavisi görenlerde fazla bulunmuştur (14). Bu durum diyetisyenlerin ve diyet listelerinin etkili olduğunu ama devamında beslenme alışkanlıkları ve hayat tarzı değişikliklerinin sürdürülmediğini düşündürmektedir.

Çalışmamızda diyet polikliğine başvuran insanlar arasında obezite prevelansının özellikle kadın cinsiyette daha yüksek olduğu saptandı. Çalışmamızda sağlıklı hayat merkezlerinde hizmet vermekte olan diyet polikliniklerinin kilo vermede etkin olduğu ikinci gelişlerde BKİ ortancalarının azaldığ 1 görülmüştür. Yll boyunca birinci basamak diyet polikliniğine başvuran kişi sayıları göz önüne alındığında bu sayının artırılmasına ve gelen kişilerin kontrol muayenelerine gelmesinin sağlanmasına yönelik çalışmalar yapılabilir.

\section{Etik Kurul Onayı}

Çalışma için Kayseri İl Sağlık Müdürlügüủnden yazılı izin ve 11.03.2020 tarih ve 2020/192 no'lu Erciyes Üniversitesi Klinik Olmayan Araştırmalar Etik Kurulu’ndan etik kurul oluru alınmıştır.

\section{Çıkar Çatışması}

Yazarların bu araştırma ve makale için herhangi bir çıkar çatışması yoktur.

Finansal Destek

Çalışma için herhangi bir finansal destek alınmamıştır.

Yazarların Makaleye Katkı Beyanı

Fikir ve tasarım; Mehmet Emin Özdemir, Serkan Yıldız, Ali Ramazan Benli, Literatür tarama ve veri toplama; Mehmet Emin Özdemir, Serkan Yıldız, Nadir Emre Ünsal, Berkan Aslan, Yorum ve Eleștirel Yaklaşım; Mehmet Emin Özdemir, Serkan Yıldız, Ali Ramazan Benli, Yazım: Mehmet Emin Özdemir, Serkan Yıldız, Sorumlu ve İletişim Yazarı; Mehmet Emin Özdemir.

\section{KAYNAKLAR}

1. Altunkaynak BZ, Özbek E. Obezite: Nedenleri ve tedavi seçenekleri. Van Tip Dergisi. 2006;13(4):138-142.

2. Çiftçi H. Obezitede tıbbi beslenme tedavisinde öğün sayısının vücut ağılık kaybı, vücut kompozisyonu ve bazı biyokimyasal bulgulara etkisi. Hacettepe Üniversitesi. Sağlık Bilimleri Enstitüsü, Beslenme ve Diyetetik Programı, Doktora tezi, Ankara, 2009.

3. Ayar K. Normal kilolu, kilolu ve obez bireylerin obezite ve obezite ilişkili hastalıklar hakkındaki bilgi düzeylerinin değerlendirilmesi ve karşılaştırılması. Uludağ Üniversitesi Tip Fakültesi. İç Hastalıkları Anabilim Dalı, Uzmanlık Tezi, Bursa, 2009.

4. Bakhshi E, Eshraghian MR, Mohammad K, Foroushani AR, Zeraati H, Fotouhi A, Siassi F, Seifi B. Socio demographic and smoking associated with obesity in adult women in Iran: Results from the National Health Survey. J Public Health. 2008;30:429-435.

5. Hajian-Tilaki KO, Heidari B. Prevalence of obesity, central obesity and the associated factors in urban population aged 20-70 years, in the North of Iran: A population-based study and regression approach. ObesRev. 2007;8:3-10.
6. James PT. Leach R, Kalamara E, Shayeghi M. The world wide obesity epidemic. Obes Res. 2001;9:228-233.

7. Deepa M, Farooq S, Deepa R, Manjula D, Mohan V. Prevalence and significance of generalized and central body obesity in an urban Asian Indian population in Chennai, India (CURES: 47). Eur J Clin Nutr. 2009;63:259-267.

8. Hill James O,Wyatt Holly R, Peters John C, Energy balance and obesity circulation. 2012;126(1):126-132.

9. 25 mayıs 2019 toplum sağlığı merkezi ve bağlı birimler yönetmeliğinde değişiklik yapılmasına dair yönetmelik. (Erişim Tarihi, 25.12.2020 https://www.resmigazete.gov.tr/ eskiler/2018/05/20180525-1.htm.)

10. Robergs RA, Roberts SO. Exercise physiology. Exercise, performence, and clinical applications. Mosby. St. Louis, 1997.

11. Gallagher D, Heymsfield SB, Heo M, Jebb SA, Murgatroyd PR, Sakamoto Y. Healthy percentage body fatranges: An approach for developing guidelines based on body massindex. Am J Clin Nutr. 2000;72:694-701.

12. World Health organization obesity and overweight Factsheet No:311, Geneva, WHO, (Erişim: http://who.nnt/mediacentral juctsmeets/Fs3117en/print.html.)

13. Abbas T, Çakır B. Birinci basamakta obeziteye yaklaşım. Ankara Medical Journal. 2012;12(1):37-41.

14. Çayır A, Atak N, Köse SK. Beslenme ve diyet kliniğine başvuranlarda obezite durumu ve etkili faktörlerin belirlenmesi. Ankara Üniversitesi Tip Fakültesi Mecmuası. 2011;64(1):1319.

15. Coşkun B. İstanbulda özel bir hastanenin diyet polikliniğìne başvuranların bazı özelliklerinin ve beslenme durumlarının değerlendirilmesi yüksek lisan tezi. Haliç Üniversitesi Sağlık Bilimleri Enstitüsü Beslenme ve Diyetetik Bölümü, 2013.

16. Global Burden of Disease Study 2015 (GBD 2015) Life Expectancy, All-Cause and Cause-Specific Mortality 1980-2015 www.thelancet.com Vol 388 October 8, 2016

17. Onat A. Keleş İ, Sansoy V, Ceyhan K, Uysal Ö et al. Rising obesity indices in 10-year follow-up of Turkish men and women: Body mass index independent predictor of coronary events among men. Türk Kardiyoloji Derneği Arşivi. 2001;29:430-436.

18. Satman I, Imamoğlu Ş, Yılmaz C. ve ark. Türkiye diyabet, hipertansiyon, obezite ve endokrinolojik hastalıklar prevalans çalışması-II. TURDEP II: Ön sonuçlar. Kronik Hastalıklar Oturumu, 13. Ulusal Halk Sağlığı Kongresi, 18-22 Ekim 2010, İzmir.

19. Hatemi H, Turan N, Arık N, Yumuk V. Türkiye Obezite ve Hipertansiyon Çalışması (TOHTA). Endokrinolojide Yönelişler Dergisi. 2002;11:1-16.

20. Kozan O, Oguz A, Abaci A, Erol C, Ongen Z, Temizhan A, Celik S. Prevalence of the metabolic syndrome among Turkish adults. Eur J Clin Nutr. 2007;61:548-553.

21. Saygın M, Öztürk Ö, Akbulut S, Kılınç F, Saygın RR. Süleyman Demirel Üniversitesi Tip Fakültesi Hastanesi diyet polikliniğine başvuran hastalarda obezite prevelansı. SDÜ Tip Fak Derg. 2015:22(3):53-59.

22. Akman M, Budak Ş, Kendi $M$. Genel dahiliye polikliniğine başvuran hastalarda obezite sıklı̆̆ı ve ilişkili sağlık problemleri. Marmara Medical Journal. 2004;17:113-120. 